\title{
A comparison of the efficacy of powered and manual toothbrushes in controlling plaque and gingivitis: a clinical study
}

This article was published in the following Dove Press journal:

Clinical, Cosmetic and Investigational Dentistry

26 February 2013

Number of times this article has been viewed

\section{Yashika Jain}

Department of Periodontology and Implantology, SGT Dental College and Research Institute, Gurgaon (Haryana), India
Correspondence: Yashika Jain 70I, Tower 7, Vipul Greens, Sohna Road, Sector 48, Gurgaon (Haryana)- I22018, India Tel +9l I24 4250463

Email denticoyashi@gmail.com
Background: Plaque is intimately related to the production and progress of dental caries and inflammatory gingival and periodontal diseases. Good plaque control facilitates the return to health for patients with gingival and periodontal diseases. Daily use of a toothbrush and other oral hygiene aids is the most dependable way to achieve oral health benefits for all patients.

Methods: A randomized clinical trial was conducted to compare the efficacy of a powered toothbrush with a manual toothbrush in controlling plaque and gingivitis over a 6-week period. The sample consisted of 60 dental students of both sexes, with ages ranging from 18 to 28 years. The samples were stratified and randomly divided into two groups of 30 by a second examiner using the coin toss method; one group used a manual toothbrush and the other group used a powered toothbrush. Each participant's gingival index, plaque index and oral hygiene index were assessed on the seventh, 14th, and 45th days on the basis of the assigned toothbrush. Collected data were analyzed and different subgroups were compared using Student's $t$-test.

Results: A paired $t$-test revealed a highly significant reduction in the gingival, plaque, and oral hygiene index scores of the manual and powered groups at the first, second, and sixth weeks ( $P$-value $<0.0001)$. An unpaired $t$-test revealed a significant reduction between the plaque index scores of the manual and powered groups at the second week $(P$-value $<0.05)$. Another unpaired $t$-test revealed a highly significant reduction between the plaque index scores of the manual and powered groups at the sixth week $(P$-value $<0.0001)$.

Conclusion: The subject group using the powered toothbrush demonstrated clinical and statistical improvement in overall plaque scores. Powered toothbrushes offer an individual the ability to brush the teeth in a way that is optimal in terms of removing plaque and improving gingival health, conferring good brushing technique on all who use them, irrespective of manual dexterity or training.

Keywords: plaque control, oral hygiene, powered toothbrush

\section{Introduction}

Plaque is intimately related to the production and progress of dental caries and inflammatory gingival and periodontal disease. ${ }^{1}$ In 1965 , Loe et $\mathrm{al}^{2}$ conducted the classic study demonstrating the cause-and-effect relationship between plaque accumulation and development of gingivitis in humans.

Good plaque control preserves oral health for a lifetime. Many clinical studies ${ }^{3-9}$ clearly indicate that the major deposits of plaque form in stagnation areas, such as the proximal areas, gingival margins, and defects in the teeth. These areas are protected from the natural cleansing mechanisms of oral tissues. Thus, emphasis 
must be placed on the effectiveness and efficacy of plaqueremoving devices used to facilitate oral hygiene in these elusive areas. ${ }^{1,3}$

The mechanical method is the most widely accepted method of plaque control. Unfortunately, effective mechanical methods of plaque control are relatively tedious, timeconsuming and, for many individuals, difficult to master. A study has suggested ${ }^{10}$ that an average person removes only about $50 \%$ of the plaque present on teeth. The first motor-driven toothbrush was displayed at the American Dental Association Convention in St Louis, MO, in 1968. It was in the 1960s that widespread use and testing of electric brushes to control plaque, gingivitis, and staining were initiated. Several well-controlled clinical trials ${ }^{3,11}$ have compared the effectiveness of various manual toothbrushes alone and of electrical and manual toothbrushes. The results of these trials have been inconclusive, but there is a strong indication that all brushes are least effective on the lingual aspects of lower molars. The correct preset angulation of the brush head, design of the brush, bristle length and material, brush diameter and, lastly, patient skill can improve plaque control in such areas. ${ }^{12-14}$ Failure to meet these parameters in manual toothbrushes has resulted in development of powered toothbrushes. These brushes work on the principle of acoustic microstreaming in which hydrodynamic forces are generated by rapid vibration of the bristles in a liquid medium, helping to disrupt plaque from the tooth surface. ${ }^{15-17}$ Electrically powered toothbrushes were first designed to mimic back-and-forth brushing techniques. Early models featured circular or elliptic motions. Currently, powered toothbrushes have oscillating and rotating motions. Since the development of the electric toothbrush, there has been a continuing controversy about whether it is more effective than a manual toothbrush. A report seemed to indicate that electric toothbrushes are superior to manual brushes in terms of removing plaque and improving gingival health. ${ }^{4}$ However, other studies conclude that conventional and electric brushes are equally effective. ${ }^{18-20}$ The aim of this study is to compare the efficacy of an electric toothbrush with that of a manual toothbrush in controlling plaque and gingivitis.

\section{Subjects and methods}

A randomized double-blind clinical trial was conducted to compare the efficacy of powered and manual toothbrushes in controlling plaque and gingivitis over a 6-week period. The sample consisted of 60 dental students of both sexes, with ages ranging from 18 to 28 years. The samples were stratified and randomized to one of the two brushing groups using the coin toss method by a second examiner who was not involved in the recording of clinical parameters. A commercially available fluoridated dentifrice (Pepsodent ${ }^{\text {B }}$ Regular) (Church and Dwight Co, Inc, Princeton, NJ, USA) was provided to the participants for use throughout the study.

Group A comprised 30 individuals who were assigned to use a manual toothbrush and were instructed to use the Modified Bass method of brushing. ${ }^{21-24}$

Group B comprised 30 individuals who were assigned to use a powered toothbrush and were instructed to use the brush with the bristles perpendicular to the gingival margin or sulcus.

\section{Inclusion criteria}

- Good general and oral health

- No periodontal therapy during the past 3 months

- Moderate gingivitis (at least $25 \%$ of test sites showing bleeding on probing)

- Ability to attend the hospital at recall intervals

- Full complement of teeth present, except third molars.

\section{Exclusion criteria}

- Poor manual dexterity

- Use of drugs that could affect the state of the gingival tissues

- Current orthodontic therapy

- Muco-gingival problems

- Five or more carious teeth requiring immediate treatment

- Use of any other supplemental plaque control measures, such as interdental cleansing aids or mouthwashes

- A habit of taking alcohol, smoking or chewing tobacco.

\section{Study protocol}

A proforma was prepared for the study, so as to have a systematic and methodical recording of all observations and information. Clinical examinations were done in a dental chair under standard conditions of light, using a mouth mirror and William's periodontal probe. Clinical findings were recorded at six sites on each tooth (distobuccal, mid-buccal, mesio-buccal, disto-lingual, mid-lingual, and mesiolingual), excluding third molars. Study design is outlined in Figure 1.

The subjects were informed about the study, and their consent to take part in the study was obtained in a prescribed form and carried out in accordance with ethical standards of the institutional committee. Brushes were distributed 


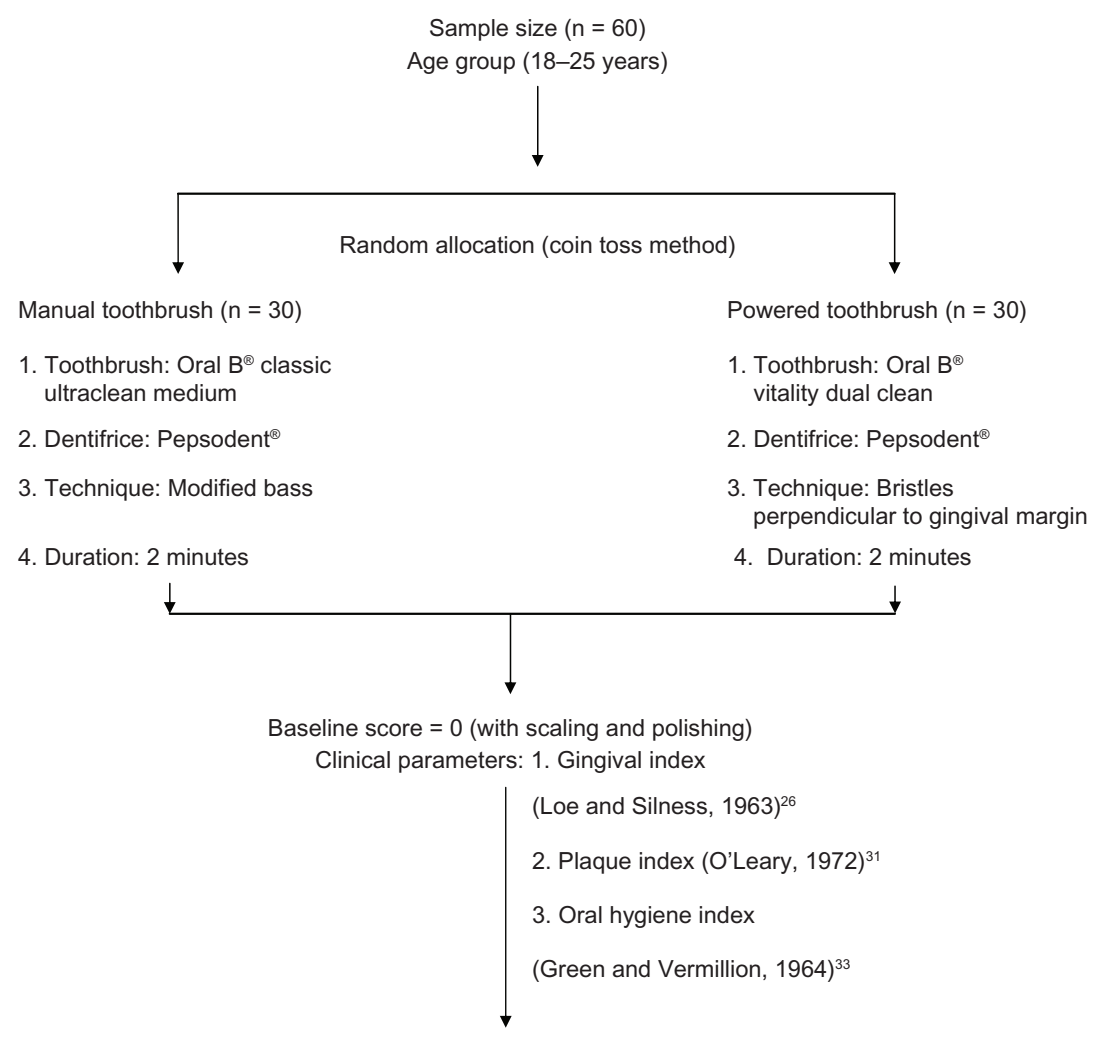

All recordings were done at 1,2 and 6 weeks

Figure I Study design showing subject characteristics, materials, and clinical methods.

randomly to the subjects by another investigator. Scaling and polishing was done for all subjects, and their baseline scores were made zero. Each subject was then instructed to brush twice a day for 2 minutes using the prescribed brushing technique and toothpaste. ${ }^{23}$ Subjects were given appointments to return at 1,2 , and 6 weeks and then discharged from the dental clinic. ${ }^{25}$

At the first week, gingival scores were recorded using the Loe and Silness Gingival Index (1963) ${ }^{26-30}$ after which a plaque disclosing agent was used. Alpha Plac DPI (Dental Product India Company, India, Mumbai) is a two-tone disclosing solution that stains bacterial plaque on teeth, enabling us to visualize plaque. It stains older plaque blue and newer plaque pink. The patient was asked to rinse the mouth with water after 2 minutes. The amount of plaque was recorded using the O'Leary Plaque Index (1972), ${ }^{31,32}$ and the Oral Hygiene IndexSimplified (OHI-S, 1964) $)^{33}$ was calculated for each subject. All the subjects were reminded to brush as instructed.

Table I Comparison of manual group's gingival, plaque, and oral hygiene index scores at I, 2, and 6 weeks

\begin{tabular}{|c|c|c|c|c|c|c|c|c|c|}
\hline & \multicolumn{3}{|c|}{ Gingival index } & \multicolumn{3}{|c|}{ Plaque index } & \multicolumn{3}{|c|}{ Oral hygiene index } \\
\hline & Mean & SD & Sig (2-tailed) & Mean & SD & Sig (2-tailed) & Mean & SD & Sig (2-tailed) \\
\hline \multicolumn{10}{|l|}{ Pair I: } \\
\hline I week versus & 0.076 & 0.084 & 0.0001 & 9.725 & 8.695 & 0.0001 & 0.232 & 0.156 & 0.0001 \\
\hline \multicolumn{10}{|l|}{2 weeks } \\
\hline \multicolumn{10}{|l|}{ Pair 2: } \\
\hline 2 weeks versus & 0.040 & $0.04 I$ & 0.0001 & 16.46 & $|6.08|$ & 0.0001 & 0.175 & 0.168 & 0.0001 \\
\hline \multicolumn{10}{|l|}{6 weeks } \\
\hline \multicolumn{10}{|l|}{ Pair 3: } \\
\hline I week versus & 0.118 & 0.098 & 0.0001 & 26.19 & 19.463 & 0.0001 & 0.408 & 0.242 & 0.0001 \\
\hline 6 weeks & & & & & & & & & \\
\hline
\end{tabular}

Notes: $P$-value is $<0.000$ I. For the gingival index and the plaque index, highly significant differences were found in all three pairings. For the oral hygiene index, significant differences were found at I, 2, and 6 weeks.

Abbreviations: SD, standard deviation; Sig (2-tailed), $P$-value. 
Table 2 Comparison of powered group's gingival, plaque, and oral hygiene index scores at I, 2, and 6 weeks

\begin{tabular}{|c|c|c|c|c|c|c|c|c|c|}
\hline & \multicolumn{3}{|c|}{ Gingival index } & \multicolumn{3}{|c|}{ Plaque index } & \multicolumn{3}{|c|}{ Oral hygiene index } \\
\hline & Mean & SD & Sig (2-tailed) & Mean & SD & Sig (2-tailed) & Mean & SD & Sig (2-tailed) \\
\hline \multicolumn{10}{|l|}{ Pair I: } \\
\hline I week versus & 0.082 & 0.047 & 0.0001 & 21.898 & 17.118 & 0.0001 & 0.321 & 0.246 & 0.0001 \\
\hline \multicolumn{10}{|l|}{2 weeks } \\
\hline \multicolumn{10}{|l|}{ Pair 2: } \\
\hline 2 weeks versus & 0.044 & 0.055 & 0.0001 & 23.542 & 14.181 & 0.0001 & 0.187 & 0.194 & 0.0001 \\
\hline \multicolumn{10}{|l|}{6 weeks } \\
\hline \multicolumn{10}{|l|}{ Pair 3: } \\
\hline I week versus & 0.126 & 0.078 & 0.0001 & 45.440 & 24.008 & 0.0001 & 0.509 & 0.217 & 0.0001 \\
\hline 6 weeks & & & & & & & & & \\
\hline
\end{tabular}

Notes: $P$-value is $<0.000$ I. Paired $t$-tests revealed a highly significant change in the gingival index scores of powered group subjects at I, 2 , and 6 weeks. Significant changes were found in the plaque index and oral hygiene index scores.

Abbreviations: SD, standard deviation; Sig (2-tailed), $P$-value.

The duration of the study was 6 weeks. Subjects returned to the dental clinic at 1,2, and 6 weeks, as appointed, and the same experimental procedures were conducted each time. Clinical parameters were recorded during each visit and submitted for statistical evaluation. The collected data were analyzed, and different subgroups were compared using Student's $t$-test; statistical analysis is shown in Tables 1-4. The mean value and $P$-value were calculated. The level of probability was set at 5\%; ie, $P<0.05$ indicated a statistically significant difference, while $P>0.05$ indicated no statistically significant difference in the results.

\section{Test products}

\section{Oral $\mathrm{B}^{\circledR}$ classic ultraclean medium manual} toothbrush

The manual toothbrush used in the study was Oral $\mathrm{B}^{\circledR}$-Classic Ultraclean Medium (Procter and Gamble Co, Cincinnati, Ohio, USA). It has wave-trim bristles specially designed to reach in between teeth for a deep clean. The soft, extra endrounded bristles are gentle to the gingival tissues, reducing the potential for tissue injury, while multi-tufted bristles provide increased cleaning efficiency. A long, narrow neck allows

Table 3 Comparison of plaque scores between manual and powered groups at 2 weeks

\begin{tabular}{lllll}
\hline Group & N & Mean & SD & $\begin{array}{l}\text { SD error } \\
\text { mean }\end{array}$ \\
\hline Manual & 30 & 60.255 & 20.670 & 3.774 \\
Powered & 30 & 44.033 & 16.482 & 3.009 \\
df & Mean & $t$ & P-value & Significance \\
& difference & & & \\
\hline Independent samples test & & & \\
58 & 16.222 & $3.36 \mathrm{I}$ & 0.0014 & $\mathrm{~S}$ \\
\hline
\end{tabular}

Notes: $P$-value is $<0.05$. An unpaired $t$-test revealed a significant difference between the plaque index scores of manual and powered groups at 2 weeks.

Abbreviations: SD, standard deviation; $d f$, degree of freedom. easy access to tooth and gingival areas, with a long handle and thumb grips providing good control and a secure grip. The brush is also provided with blue indicator bristles.

\section{Oral $\mathrm{B}^{\circledR}$ vitality dual clean powered toothbrush}

The Oral B ${ }^{\circledR}$ Vitality Dual Clean (Procter and Gamble Co, Cincinnati, Ohio, USA) comes with two Oral-B Dual Clean brush heads, which oscillate or rotate at a frequency of 7,600 oscillations per minute. The Dual Clean brush head provides cleaning, freshening, and gum care with two distinct, moving sections, and the interdental tips penetrate hard-to-reach areas. The brush works on the principle of acoustic microstreaming property, which results in damage to the attachment apparatus of the plaque microorganisms. The brush head is provided with indicator bristles; with proper brushing twice a day, the color will disappear halfway down the bristles over a 3-month period.

\section{Results}

All 60 subjects successfully completed the study period of 45 days. None dropped out, and all the subjects maintained their recall appointments.

Table 4 Comparison of plaque scores between manual and powered groups at 6 weeks

\begin{tabular}{lllll}
\hline Group & N & Mean & SD & $\begin{array}{l}\text { SD error } \\
\text { mean }\end{array}$ \\
\hline Manual & 30 & 43.786 & 22.645 & 4.134 \\
Powered & 30 & 20.491 & 10.334 & 1.887 \\
df & $\begin{array}{l}\text { Mean } \\
\text { difference }\end{array}$ & $\boldsymbol{t}$ & P-value & Significance \\
$\begin{array}{llll}\text { Independent samples test } \\
58\end{array}$ & & & \\
\hline
\end{tabular}

Notes: $P$-value is $<0.0001$. An unpaired $t$-test revealed a highly significant difference in the plaque index scores of the manual and powered groups at 6 weeks. Abbreviations: SD, standard deviation; $\mathrm{df}$, degree of freedom. 


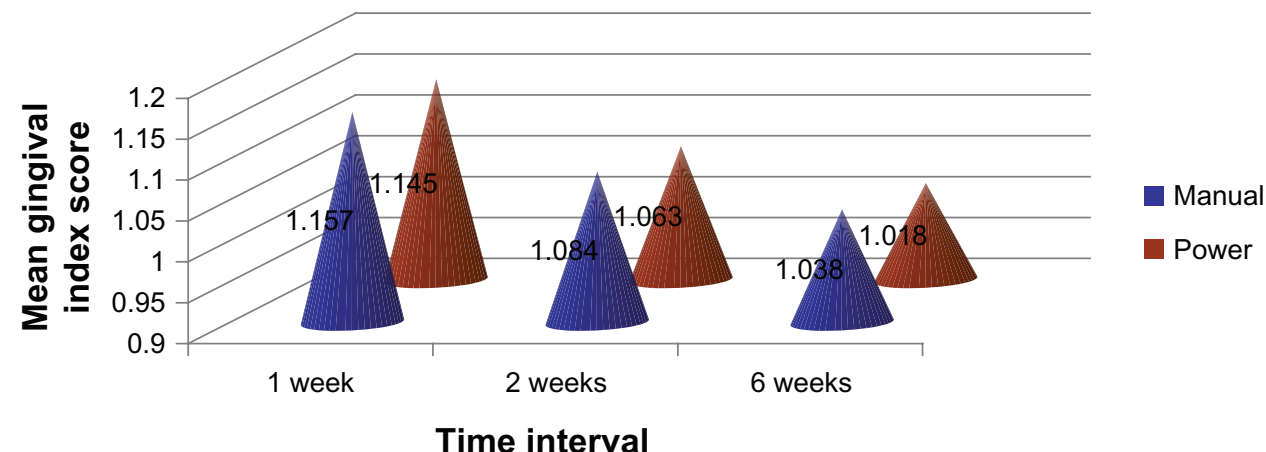

Figure 2 Comparison of gingival index scores between subjects using manual and electric-powered toothbrushes.

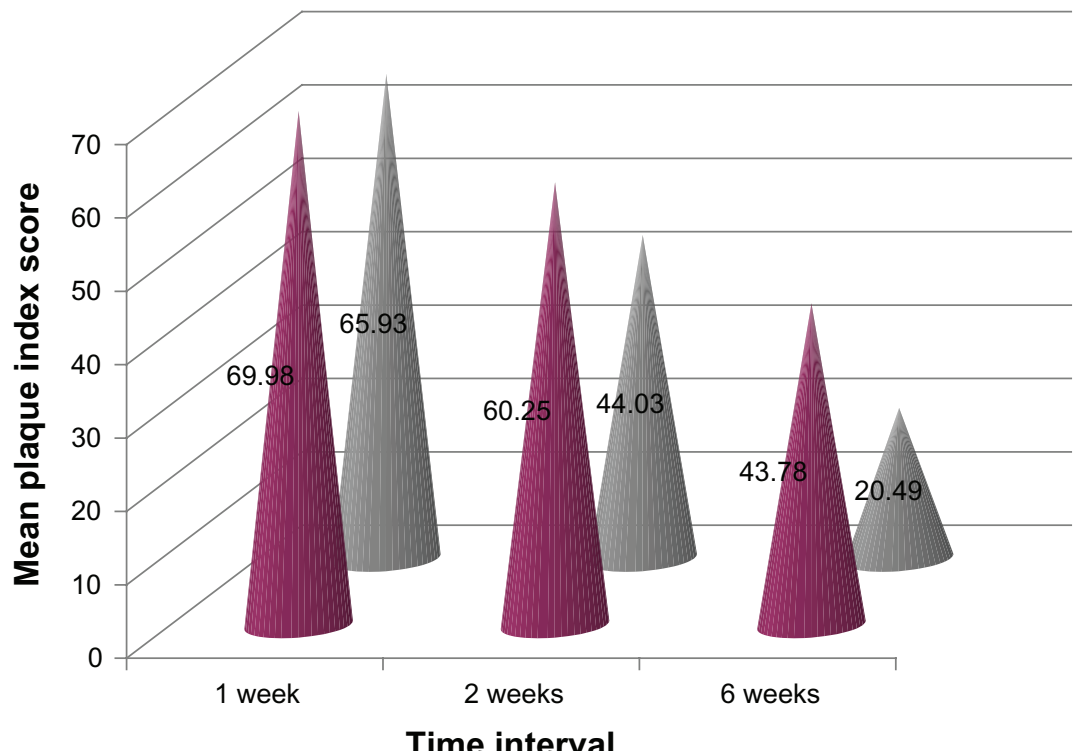

Figure 3 Comparison of plaque index scores between subjects using manual and electric-powered toothbrushes.

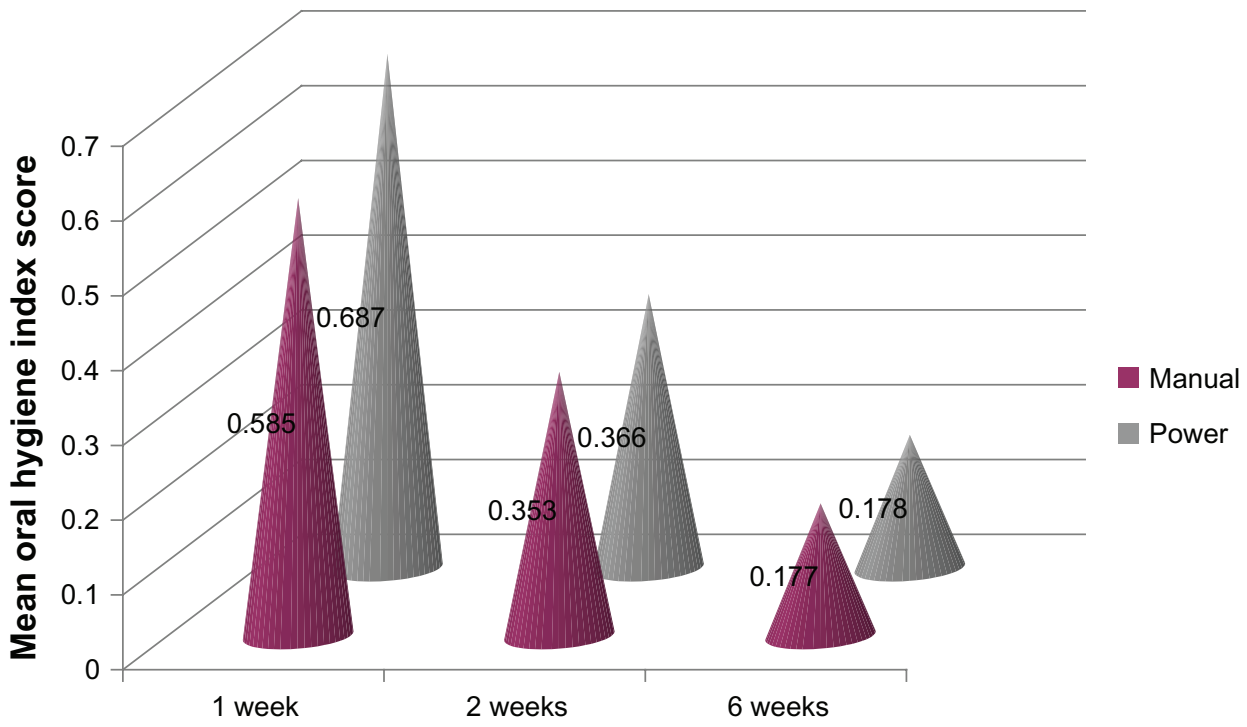

Time interval

Figure 4 Comparison of oral hygiene index scores between subjects using manual and electric-powered toothbrushes. 
The gingival index for the manual group at 1 week was $0.0726 \pm 0.084$, which was reduced to $0.118 \pm 0.098$ at the end of the study (Table 1). For the powered group, the mean gingival index at 1 week was $0.082 \pm 0.047$, which was reduced to $0.126 \pm 0.078$ at the end of the study (Table 2). Plaque scores also decreased from $9.725 \pm 8.695$ to $26.194 \pm 19.463$ for manual group (Table 1), and from $21.898 \pm 17.118$ to $45.440 \pm 24.008$ for the powered group (Table 2). The manual group's oral hygiene index score at 1 week was $0.232 \pm 0.156$, which was reduced to $0.408 \pm 0.242$ at the end of the study (Table 1). Among the powered group, the oral hygiene index showed a reduction from $0.321 \pm 0.246$ at 1 week to $0.509 \pm 0.217$ at the end of the study (Table 2). All the clinical parameters showed a significant reduction from the baseline to the end of the study. The parameters were evaluated using the Student's $t$-test. An unpaired $t$-test revealed a significant difference between the plaque index scores of the manual group and the powered group, with mean values of $60.255 \pm 20.670$ and $44.033 \pm 16.482$, respectively, at 2 weeks (Table 3 ) and $43.786 \pm 22.645$ versus $20.491 \pm 10.334$ at 6 weeks (Table 4).

Overall mean reductions in gingival, plaque, and oral hygiene index scores for the manual and powered groups are presented in Figures 2-4.

\section{Discussion}

In the present study, when comparing the plaque index scores of the manual and powered groups, subjects in the powered group showed highly significant results on the 14th and 42nd days. This implies that the powered toothbrush removed supra gingival plaque better than the manual toothbrush over the 42-day period, which is comparable to studies done by Breuer et al, ${ }^{34}$ Mayer, ${ }^{35}$ and Niederman et al. ${ }^{36}$ This positive result may be due to the acoustic microstreaming property of the electric toothbrush, which results in damage to the attachment apparatus of microorganisms that form plaque. ${ }^{16}$ It could also be attributed to the oscillating, rotating movement of the brush head with a frequency of $7600 \mathrm{rpm}$, enabling enhanced cleaning action; and to the presence of interproximal bristles, which clean better.

In the present study, gingival status was assessed using the Loe and Silness gingival index (1963). ${ }^{26}$ The same index was used in studies by Brockmann et al, ${ }^{27}$ Heasman et al, ${ }^{28}$ Barnes et al, ${ }^{29}$ and Grossman et al. ${ }^{30}$

The mean gingival index for the manual group fell from 1.156 on the seventh day to 1.038 on the 42 nd day, while the powered group showed a decline in mean gingival index scores from 1.145 on the seventh day to 1.018 on the 42nd day. In comparing the gingival index scores for these groups, both showed a reduction in gingival inflammation, but it was not statistically significant. This is in contrast to a study conducted by Baab DA, ${ }^{37}$ in which a group using an electrical brush had a statistically significant reduction in gingival index score to that of a manual toothbrush.

In the present study, the oral hygiene score was assessed using the Oral Hygiene Index-Simplified, created by Green and Vermillion, ${ }^{33}$ to assess calculus and debris. The oral hygiene score for the manual group was reduced from 0.596 on the seventh day to 0.196 on the 42 nd day; the powered group's mean oral hygiene score decreased from 0.703 on the seventh day to 0.18 on the 42 nd day. No statistically significant difference was found between the two groups.

In conclusion, a definite and gradual improvement in the reduction of plaque and health of gingiva was observed in both groups by the sixth week of this 42 -day study. The lack of association between plaque scores without a commensurate resolution in gingivitis was also seen in studies conducted by Stoltze and Bay, ${ }^{25}$ Khocht et al, ${ }^{38}$ and Ainamo et al. ${ }^{39}$ Likely reasons include inter subject variation in the pathogenicity of plaque and an exaggerated effect of plaque reduction that results from volunteers paying particular attention to cleaning their teeth on the days of examination. ${ }^{28}$

The findings of this study lend support to the argument that, when compared with a manual toothbrush, a powered toothbrush has the potential to improve oral hygiene by achieving plaque reduction. Powered toothbrushes offer an individual the ability to brush the teeth optimally to remove plaque and improve gingival health, conferring good brushing technique on all who use them, irrespective of manual dexterity or training.

\section{Limitations and recommendations}

For such clinical trials, dentifrices without a known plaquesuppressing effect should be recommended. Studies targeting the general population or patients with specific periodontal problems should be considered. Longitudinal studies are needed to assess the long-term effectiveness of powered brushes on plaque and gingivitis.

\section{Disclosure}

The author reports no conflicts of interest in this work.

\section{References}

1. Echeverria JJ, Sanz M. Mechanical supragingival plaque control. In: Lindhe J, Karring T, Lang NP, editors. Clinical Periodontology and Implant Dentistry, 4th ed. Munksgaard, Denmark: Blackwell Publishing; 2003:449-463. 
2. Loe H, Theilade E, Jensen SB. Experimental gingivitis in man. J Periodontol. 1965;36:177.

3. Perry DA, Schmid MO. Plaque control. In: Carranza FA, Newman MG, editors. Clinical Periodontology, 8th ed. WB Saunders Co; 1995:493-508.

4. Scopp IW, Cohen G, Cancro LP, Bolston S. Clinical evaluation of a newly designed contoured toothbrush. J Periodontol. 1976;47:87-90.

5. Critchley P. Dental plaque, oral disease and plaque control. J Ind Dent Assoc. 1978;50:43-49.

6. Gibson MT, Joyston-Bechal S, Smales FC. Clinical evaluation of plaque removal with a double headed toothbrush. J Clin Periodontol. 1988 15:94-98. Agerholm DMF. A clinical trial to evaluate plaque removal with a double headed toothbrush. Br Dent J. 1991;170:411-413.

7. Shory NL, Mitchell GE, Jamison HC. A study of the effectiveness of two types of toothbrushes for removal of oral accumulations. JAmDent Assoc. 1987;115:717-720.

8. Kambu PP, Levy SM. An evaluation of the effectiveness of four mechanical plaque removal devices when used by a trained care provider. J Spec Care Dent. 1993;13:9-13.

9. Frandsen A, Barbano J, Soumi J, Chang J, Houston R. A comparison of the effectiveness of Charters, Scrub, and Roll methods of tooth brushing in removing plaque. J Dent Res Scand. 1972;80:267-271.

10. Jepson $\mathrm{S}$. The role of manual toothbrushes in effective plaque control: Advantages and Limitations. In: Lang NP, Attstrom R, Loe H, editors. Proceedings Of The European Workshop On Mechanical Plaque Control. London: Quintessence, 121-37.

11. Chava VK. Clinical efficacy of curved bristle brush and straight bristle brush. J Periodontal. 2000;71:785-789.

12. Glavind L, Zeuner E. The effectiveness of a rotary electric toothbrush on oral cleanliness in adults. J ClinPeriodontol. 1986;13:135-138.

13. Shibly O, Schifferle RE, Ciamio SG, Tarakji M, Mather ML. A clinical comparison of 2 electric toothbrush designs. J Clin Periodontol. 1997:24:260-263.

14. Vander Weijden GA, Danser MM, Nijboer A, Timmerman MF, vanderVelden U. The plaque-removing efficacy of an oscillating/rotating toothbrush: A short-term study. J Clin Periodontol. 1993;20:273-278.

15. McCracken GI, Heasman L, Stacey F, Kelly PJ, Heasman PA. Testing the efficacy of plaque removal of a prototype brush head for a powered toothbrush. J Clin Periodontol. 2000;27:542-548.

16. McInnes C, Engel D, Martin RW. Fimbria damage and removal of adherent bacteria after exposure to acoustic energy. Oral Microbiol Immunol. 1993;8:277-282.

17. Walsh M, Heckman B, Leggott P, Armitage G, Robertson PB. Comparison of manual and power toothbrushing, with and without adjunctive oral irrigation, for controlling plaque and gingivitis. $J$ Clin Periodontol. 1989;16:419-427.

18. Deery C, Heanue M, Deacon S, et al. The effectiveness of manual versus powered toothbrushes for dental health: a systematic review. J Dent. 2004;32:197-211.

19. Verkaik MJ, Busscher HJ, Rustema-Abbing M, Slomp AM, Abbas F, van der Mei HC. Oral biofilm models for mechanical plaque removal. Clin Oral Investig. 2010;14:403-409.

20. McKendrick AJ, Barbenel LM, McHugh WD. A two-year comparison of hand and electric toothbrushes. Journal of Periodontal Research. 1968;3:224-231.
21. Van der Weijden GA, Timmerman MF, Danser MM, Van der Velden U. Relationship between the plaque removal efficacy of a manual toothbrush and brushing force. J Clin Periodontol. 1998;25:413-416.

22. Bastiaan RJ. Comparison of the clinical effectiveness of a single and a double headed toothbrush. J Clin Periodontol. 1984;11:331-339.

23. Tritten CB, Armitage GC. Comparison of a sonic and a manual toothbrush for efficacy in supragingival plaque removal and reduction of gingivitis. J Clin Periodontol. 1996;23:641-648.

24. Hanioka T, et al. Study on the effectiveness of an electric toothbrush (Braun Oral-B D5) for plaque removal and gingival improvement compared to a manual toothbrush. J Clin Dent. 1993;6:113-116.

25. Stoltze K, Bay L. Comparison of a manual and a new electric toothbrush for controlling plaque and gingivitis. $J$ Clin Periodontol. 1994;21:86-90.

26. Loe H, Silness J. Periodontal disease in Pregnancy I. Prevalence and Severity. Acta Odontol Scand. 1963;21:533-551.

27. Brockmann LB, Hanson CC, Killoy WJ. The effects of an ultrasonic toothbrush on plaque accumulation and gingival inflammation. J Clin Periodontol. 1998;25:375-379.

28. Heasman PA, Stacey F, Heasman L, Sellers P, Macgregor IDM, Kelly PJ. A comparative study of the Philips HP 735, Braun/Oral B D7 and the Oral B 35 Advantage toothbrushes. $J$ Clin Periodontol. 1999;26:85-90.

29. Barnes CM, Weatherford TW 3rd, Menaker L. A comparison of the Braun Oral-B Plaque Remover (D5) electric and a manual toothbrush in affecting gingivitis. $J$ Clin Dent. 1993;4:48-51.

30. Grossman E, Dembling W, Proskin HM. A comparative clinical investigation of the safety and efficacy of an oscillating/rotating electric toothbrush and a sonic toothbrush. J Clin Dent. 1995;6:108-112.

31. O'Leary TJ, Drake RB, Naylor JE. The plaque control record. J Periodontal. 1972;43:38.

32. Hotta M, Aono M. A clinical study on the control of dental plaque using an electronic toothbrush with piezo-electric element. Clin Prev Dent. 1992;14:16-18.

33. Greene JC, Vermillion JR. The Simplified Oral Hygiene Index. $J A m$ Dent Assoc. 1964;68:7-13.

34. Breuer MM, Cosgrove R, Hardy D, Nizel A, Schechter SA, Watts MK. A comparison of the plaque-removal efficacies of two electric toothbrushes. Quintessence Int. 1989;20:501-504.

35. Mayer R. Electric toothbrush manual toothbrush, a comparison test ZWR. 1990;99:188-192. German.

36. Niederman R; ADA Council on Scientific Affairs; ADA Division of Science; Journal of the American Dental Association. Manual versus powered toothbrushes: the Cochrane review. J Am Dent Assoc. 2003;134:1240-1244.

37. Baab DA, Johnson RH. The effect of a new electric toothbrush on supragingival plaque and gingivitis. J Periodontol. 1989;60:336-341.

38. Khocht A, Spindel L, Person P. A comparative clinical study of the safety and efficacy of three toothbrushes. J Periodontol. 1992;63:603-610.

39. Ainamo J, Xie Q, Ainamo A, Kallio P. Assessment of the effect of an oscillating/rotating electric toothbrush on oral health: a 12-month longitudinal study. J Clin Periodontol. 1997;24:28-33.
Clinical, Cosmetic and Investigational Dentistry

\section{Publish your work in this journal}

Clinical, Cosmetic and Investigational Dentistry is an international, peer-reviewed, open access, online journal focusing on the latest clinical and experimental research in dentistry with specific emphasis on cosmetic interventions. Innovative developments in dental materials, techniques and devices that improve outcomes and patient satisfac-

\section{Dovepress}

tion and preference will be highlighted. The manuscript management system is completely online and includes a very quick and fair peerreview system, which is all easy to use. Visit http://www.dovepress. com/testimonials.php to read real quotes from published authors. 